\title{
Interactive comment on "Simulation Improvements of ECHAM5-NEMO3.6 and ECHAM6-NEMO3.6 Coupled Models Compared to MPI-ESM and the Corresponding Physical Mechanisms" by Shu Gui et al.
}

Shu Gui et al.

1323842528@qq.com

Received and published: 30 September 2018

Thank you for your constructive comments. We have revised the manuscript as you suggest. The authors' response and marked-up version are included in the supplement file. If there is any other question about the manuscript revisions, please let me know.

Best regards

Gui Shu and co-authors 
Please also note the supplement to this comment:

https://www.geosci-model-dev-discuss.net/gmd-2018-130/gmd-2018-130-AC5-

supplement.pdf

Interactive comment on Geosci. Model Dev. Discuss., https://doi.org/10.5194/gmd-2018-130, 2018. 